\title{
Therapeutic Evolution and the Challenge of Rational Medicine
}

\section{Citation}

Greene, Jeremy A., David S. Jones, and Scott H. Podolsky. 2012. “Therapeutic Evolution and the Challenge of Rational Medicine." New England Journal of Medicine 367, no. 12: 1077-1082.

\section{Published Version}

doi:10.1056/NEJMp1113570

\section{Permanent link}

http://nrs.harvard.edu/urn-3:HUL.InstRepos:14393968

\section{Terms of Use}

This article was downloaded from Harvard University's DASH repository, and is made available under the terms and conditions applicable to Other Posted Material, as set forth at http:// nrs.harvard.edu/urn-3:HUL.InstRepos:dash.current.terms-of-use\#LAA

\section{Share Your Story}

The Harvard community has made this article openly available.

Please share how this access benefits you. Submit a story.

\section{Accessibility}




\section{Therapeutic Evolution and the Challenge of Rational Medicine}

Jeremy A. Greene, M.D., Ph.D., David S. Jones, M.D., Ph.D., and Scott H. Podolsky, M.D.

\section{The first article in the inaugural issue of the New England Journal of Medicine and Surgery, in January 1812, was a treatise on angina pectoris by John Warren, a founding member of Harvard}

Medical School. Warren's clinical descriptions should still sound familiar to anyone who has treated coronary artery disease. His therapeutic strategies, in contrast, appear downright bizarre. $\mathrm{He}$ treated one patient, a "plethoric" clergyman, with stimulants, bloodletting (see Fig. 1), and topical ether, then with more bloodletting, opium, powerful laxatives, and caustic agents that blistered

A slide show is the skin over his steravailable at num. As the patient's NEJM.org anginal attacks increased in frequency and intensity, Warren tried asafetida (see Fig. 2) - a botanical resin known as "Devil's dung" for its sulfuric, excremental smell - and additional caustics such as silver ni- trate to provoke draining blisters on his thighs and arms. With the clinical picture worsening, Warren sent his patient on a therapeutic voyage to Georgia, "where he passed the winter, and suffered less violent attacks than in a more northern climate" (1812a; see box for cited Journal articles). When the minister returned to Boston and his attacks again intensified, Warren added arsenic and bled him vigorously, to no avail. Before his patient's death, Warren noted that the minister's condition improved somewhat with the use of tobacco.

Seen at a remove of two centuries, Warren's treatments seem excessive, even futile. Apart from opiates - which still have a role in treating severe angina - they have nothing in common with today's cardiovascular therapeutics. Thrombolytic agents, antiplatelet drugs, beta-blockers, stents, and bypass surgery - the mechanisms of which are understood in many cases at a molecular level - have demonstrably improved the patient's odds of surviving and leading a productive life, even after a major heart attack. Yet an examination of the history of therapeutic practice can do more than simply chart our progress over the past two centuries. It can also demonstrate how change occurs in medicine, revealing what has been gained and what opportunities have been lost along the way.

As generations of physicians have sought more rational bases for medical practice, they have swung between the poles of enthusiasm and skepticism. They have sought therapeutic power 


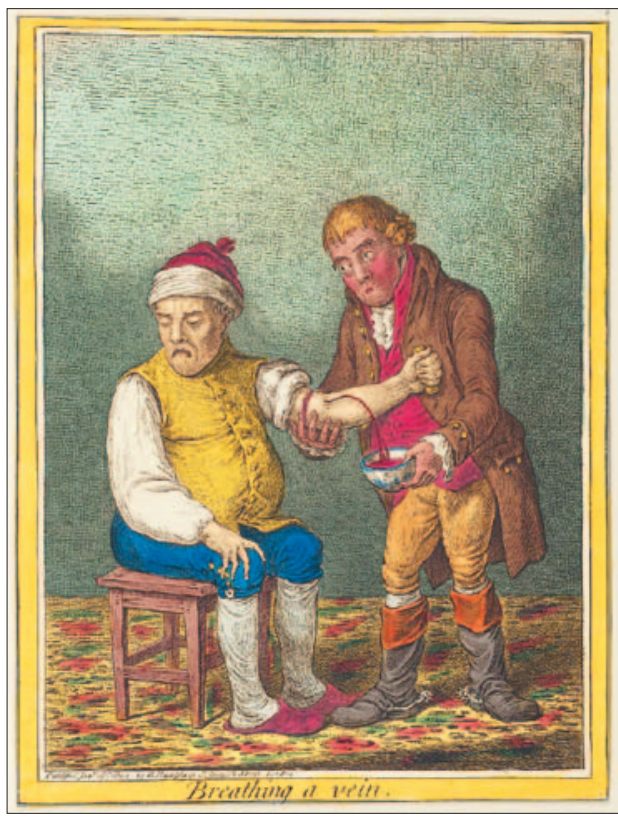

Figure 1. Bloodletting in the Early 19th Century.

This caricature by James Gillray (1757-1815) illustrates the common practice of bloodletting ("breathing a vein") to help cure disease. (Published by H. Humphrey, St. James's Street, London, January 28, 1804.)

and confidence by reducing their scope of vision toward more precise targets of intervention and measures of success, sometimes losing sight in the process of the broader significance of therapy within the lives of patients and populations. A historical approach to therapeutics, as examined through the pages of the Journal, can help to redirect our attention toward the practical context in which medicine has evolved.

\section{THERAPEUTICS IN CONTEXT}

Although many practices of 19thcentury physicians sound macabre to us today, it is important to understand that their therapeutics actually worked - within the context of a very different way of thinking about disease and therapeutic efficacy. ${ }^{1}$ Both patients and doctors in 1812 generally believed that health and disease were related to the balance and free flow of the four humors: blood, phlegm, black bile, and yellow bile. They also shared expectations about therapeutics: a remedy should provoke powerful symptoms to restore balance and flow. A patient who was feverish, flushed, and delirious from malaria could be calmed and cooled, at least to the touch, by bleeding. Patients who were convinced that their suffering stemmed from intestinal obstructions were gratified by the voluminous vomiting and diarrhea that emetics and cathartics produced. Moreover, treatments were tailored to individual characteristics, such as age, habits, occupation, and locale.

Humoral therapeutics took a distinctly American turn in the young republic. Warren's seemingly buckshot therapeutic approach evokes caricatures of the practitioner of "heroic medicine," an approach commonly associated with Philadelphia's Benjamin Rush. Heroic medicine employed dramatic interventions to "shock" the body back into a state of humoral balance and health. The more dire the disease, the more heroic the intervention.

An 1812 article in the Journal advised "copious bleeding" of patients with gunshot wounds - a therapeutic strategy that seems oxymoronic until we recall that physicians' principal concern (once the initial hemorrhage was stayed) lay in preventing suppuration and gangrene. Since these processes were known to follow inflammation and fever, and bloodletting reduced visible signs of both, physicians had a moral imperative to bleed as much as was tolerable in order to save life and limb (1812d). Therapeutic rationality took many forms.
SKEPTICISM, ENTHUSIASM, AND THE THERAPEUTIC IMPERATIVE

The Journal's inaugural issue featured a largely favorable review of Rush's teachings, along with the lament that "were our knowledge of diseases and their treatment as definite as our acquaintance with the forms and laws of matter; there would be neither doubt nor diversity in medical practice, and mankind would be entitled to reach the allotted period of three score years and ten" (1812c).

Yet doubt and diversity were on the rise. Boston soon became home to a skeptical practice style that directly disparaged Rush's heroic approach. Even in the Journal's first issue, Jacob Bigelow critiqued the varied rationales justifying existing treatments for burns and appealed for empirical evidence to support the "negative mode of treating burns, which should

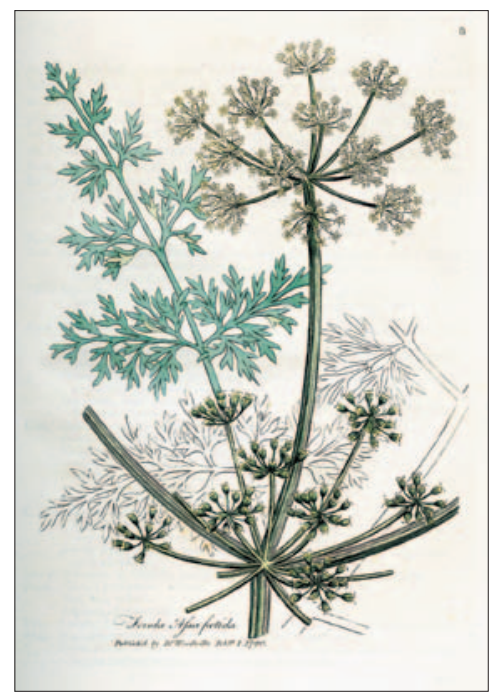

Figure 2. The Asafetida Plant.

The resin obtained from this plant, also known as "Devil's dung" because of its putrid odor, was used in a wide variety of therapeutics. A knowledge of botany, including illustrated guides to medicinal plants, was considered essential to medical practice in the early 19th century. (Published by Dr. Woodville, February 1, 1790.) 


\section{Historical Journal Articles Cited.}

New England Journal of Medicine and Surgery, and the Collateral Branches of Science 1812a. Warren J. Remarks on angina pectoris. 1:1-11.

1812b. Bigelow J. Observations and experiments on the treatment of injuries occasioned by fire and heated substances. 1:52-64.

1812c. Sixteen introductory lectures, to courses of lectures upon the institutes and practice of medicine, with a syllabus of the latter. To which are added, two lectures upon the pleasures of the senses and of the mind, with an inquiry into their proximate cause. Delivered in the University of Pennsylvania. By Benjamin Rush, M.D. Philadelphia; Bradford and Innskeep, 1811. (Book review.) 1:81-6.

1812d. On gun-shot wounds. 1:344-58.

Boston Medical and Surgical Journal

1835. Dr. Bigelow's discourse. 12:413-5.

1846. Bigelow HJ. Insensibility during surgical operations produced by inhalation. 35:309-17.

1861. Ware J. Lectures on general therapeutics. 63:489-97.

1912a. Worcester A. Past and present methods in the practice of medicine. 166:159-64.

1912b. Clinical lectures on the acute abdomen. By William Henry Battle. New York: William Wood and Co., 1911. (Book review.) 166:257.

1912c. Morse GW. Three unusual cases of appendicitis. 167:16-9.

1912d. Blood vessel surgery and its application. By A.C. Guthrie. New York: Longmans, Green, and Co., 1912. (Book review). 167:96.

1912e. Osgood RB, Soutter R, Bucholz H, Danforth MS. Report of progress in orthopedic surgery. 167:195-8.

1912f. Post A. The present status of Salvarsan. 167:320-3.

1912g. Newell FS. Indications for the major obstetrical operations. 167:383-9.

1912h. Boos WF. The Salvarsan-calomel treatment of syphilis. 167:389-93.

1912i. McGurn WJ. A new device for the safe and certain administration of Salvarsan. 167:696-9.

1912j. Balboni GM. The treatment of pulmonary tuberculosis by artificial pneumothorax, according to the method of Forlanini - with a report of twenty-one cases. 167:928-33.

New England Journal of Medicine

1960a. Perles of great price. 262:96.

1960b. The life of trade. 263:307-8.

1961a. Dowling HF. The pharmaceutical industry and the doctor. 264:75-9.

1961b. Senator Kefauver presents his bill. 264:1312-3.

1961c. Ethical drugs — reflections on the inquiry. 265:1015-6.

1962a. New products parade. 266:1011.

1962b. A sleep but no forgetting. 267:417-8.

2006. Kim JY, Farmer P. AIDS in 2006 - moving toward one world, one hope? 355:645-7.

2009. Bryan CS, Podolsky SH. Dr. Holmes at 200 — the spirit of skepticism. 361:846-7.

2011a. Sepkowitz KA. One hundred years of Salvarsan. 365:291-3.

2011 b. Avorn J. Learning about the safety of drugs - A half-century of evolution. 365:2151-3.

consist in letting them alone, or in leaving the process to nature" (1812b). Bigelow would later elaborate his thoughts on the vis med- icatrix naturae, the "healing force of nature," in the oft-cited "Discourse on Self-Limited Diseases" (1835).
Many factors fostered the spread of skepticism about therapeutics during the first half of the 19th century. American doctors admired the work of Pierre Louis and the "numerical method" taught at La Charité Hospital in Paris, where Louis tallied up outcomes in patients with pneumonia who were treated with or without bloodletting and found no measurable difference. The local marketplace played a role as well: "regular" physicians faced competition from homeopaths, hydropaths, naturopaths, eccentrics, and other sectarians who lampooned the traditional devotion to the lancet and offered less painful alternatives. By the Journal's 50th anniversary, the vis medicatrix naturae had become so central to U.S. therapeutic practice that Harvard's John Ware devoted the first 2 parts of a 21-part series on "General Therapeutics" to explicating the concept (1861). The philosophy of therapeutic skepticism was perhaps most famously articulated by Oliver Wendell Holmes, who remarked in 1860 that "if the whole materia medica, as now used, could be sunk to the bottom of the sea, it would be all the better for mankind and all the worse for the fishes" (2009).

Though therapeutic skepticism was an animating force in American medicine, its more extreme incarnation, therapeutic nihilism, was never a viable solution for physicians. Doctors could not abandon heroic medicine overnight simply on the basis of numerical "proof" that bloodletting didn't work — for no doctor worthy of the title could morally countenance doing nothing when confronted with suffering patients. Therapeutics, embedded in both matters of proof and mat- 
ters of practice, could change only as much as medical theory and patient expectations allowed. As Holmes observed, "there is a changeable as well as a permanent element in the art of healing; not merely changeable as diseases vary, or as new remedies are introduced, but changeable by the going out of fashion of special remedies, by the decadence of popular theory from which their fitness was deduced, or other cause not more significant" (2009).

Heroic therapies faded only as physicians shifted their enthusiasm to new interventions - notably, quinine, alcohol, and other purported stimulants in the mid-to-late 19th century. ${ }^{2}$ Quinine, for instance, became popular as both a specific treatment for malaria and a general "tonic." Just as cathartics and bleeding made sense to doctors concerned about fever, obstruction, and humoral balance, quinine and other stimulants made sense in a medical world increasingly dominated by consumption and other diseases characterized by loss of vital energies. And mid19th-century physicians didn't abandon the iconic forms of heroic therapeutics - mercury and the lancet - without a fight.

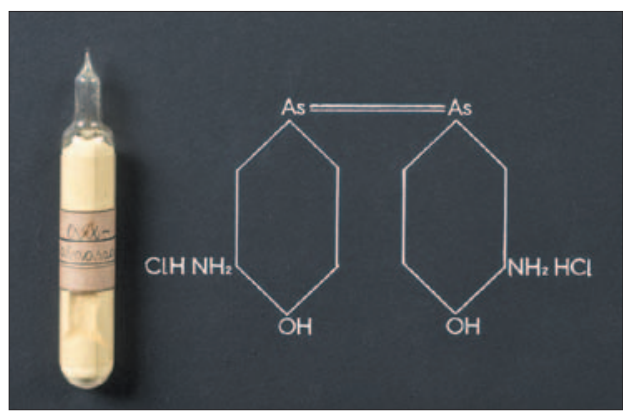

Figure 3. An Ampule Containing Salvarsan, and Its Chemical Structure.

The arsenical compound Salvarsan (widely known as Compound 606) was synthesized and tested by Ehrlich and his assistants and was used to treat syphilis.
Even as Union Army physicians used less and less calomel in coping with Civil War casualties, they rallied to court-martial the Surgeon General in 1863 after he moved to ban the use of this mercury compound. And even after physicians had tempered their heroic therapies, they remained committed to tailoring remedies to patients' idiosyncrasies.

\section{THERAPEUTIC REVOLUTIONS}

By the mid-19th century, however, the focus on patients' particularities began to give way to interest in the specific causes of disease. Motivated by breakthroughs in cellular pathology, pathophysiology, and especially bacteriology, doctors increasingly came to see diseases as specific entities, each with its own specific causes, manifested as characteristic syndromes. This new model prompted doctors to seek therapies tailored to the disease and not the patient. ${ }^{2}$ This transformation, like other "therapeutic revolutions," took a complex course. Old ideas about therapeutic skepticism and individualization endured, and the promise of new therapies often didn't materialize for decades.

Consider the "revolution" launched by William Morton's 1846 demonstration of ether anesthesia at Massachusetts General Hospital. Described in the Journal on November 18, 1846, ether anesthesia was one of the first significant medical discoveries to cross the Atlantic from west to east and transform medical practice in both North America and Europe (1846). The transformation was, however, neither rapid nor smooth. Anesthesia enabled dramatic innovation in surgery, but it also increased the dangers of surgery. Before the use of antiseptic and aseptic techniques, op- erative mortality and postoperative infections took a staggering toll, as any Civil War surgeon could recount. Many surgeons, long inured to the pain they inflicted, wondered whether pain relief justified the unknown risks from the new anesthetic agents. Surgical decision making required a delicate "calculus of suffering" in which the surgeon weighed the factors in each case, and the anesthetic "revolution" followed a more halting course than one might imagine. ${ }^{3}$

By the Journal's centennial in 1912, however, surgeons had mastered aseptic techniques and the rituals of the modern operating room. The Journal abounded with accounts of innovations in abdominal surgery (1912b, 1912c), vascular surgery (1912d), orthopedic surgery (1912e), obstetric and gynecologic surgery (1912g), and thoracic surgery (1912j) that had previously been inconceivable. The revolution in surgery required not just ether but a careful articulation of diverse processes - anesthesia and asepsis, but also the choreography of surgeons, anesthetists, scrub nurses, linens, autoclaves, and redesigned hospitals. Even those revolutions that in retrospect seem most obvious followed a complicated course.

A similar story played out in the realm of pharmacotherapy in the early 20th century. During the Journal's centennial year, there were effusive reports on the innovations in antibacterial chemotherapy emerging from the Berlin laboratory of Paul Ehrlich, who sought a "magic bullet" a specific therapeutic that would selectively poison a pathogenic microbe while leaving the host unharmed. After 605 failures, the antisyphilitic Compound 606 Salvarsan — was widely hailed 


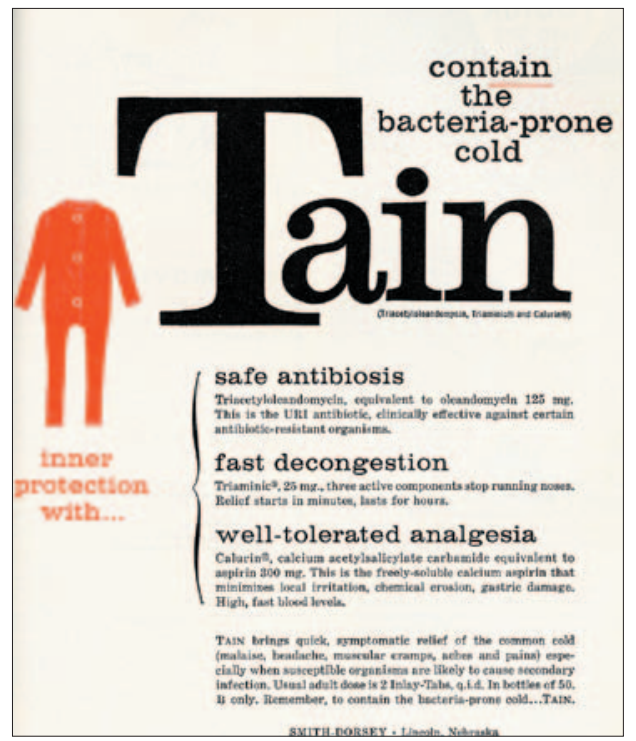

Figure 4. A 1960 Advertisement for Tain.

The combination antibiotic Tain was advertised for the treatment of colds, which by the early 1960s was already considered inappropriate by infectious disease experts.

when it was launched (2011a) (see Fig. 3). By 1912, Salvarsan was available in large quantities to most U.S. physicians and patients.

Salvarsan became an exemplar of the new strategy whereby treatments were tailored not to individual patients but to specific diseases. Yet, revisited today, the 1912 accounts of Salvarsan in the Journal challenge simple interpretations of therapeutic revolution. Doctors struggled to develop safe ways to deliver the intravenous medication (1912i). They lamented that Salvarsan's specificity was more theoretical than empirical: the drug clearly did not work against all cases of syphilis (1912f, 1912h). Its effects were not nearly as specific to Treponema pallidum as had been hoped: patients often had terrible side effects from the arsenical compound. Nor did it transform therapeutic practice overnight: instead of replacing mercury with Salvarsan, many doctors used the new drug alongside calomel.
Salvarsan also showed the conceptual limits of a reductionist approach to medicine. Syphilis was not simply a collection of signs and symptoms that followed infection by a particular pathogen. It was a complex social phenomenon, involving shame, stigma, and other moral complications associated with sexually transmitted infection. ${ }^{4}$ Although Salvarsan provided relief to some patients, it offered only a partial solution to a complex disease. Preserved in the archives of the Journal for that year are the voices of physicians who worried that too much of traditional practice had been lost in focusing on treating diseases and not patients. Should not students, one author worried, "also be taught the art of relieving, of soothing and comforting those who suffer, and of steadying and supporting those who walk in the valley of the shadow?" (1912a).

\section{THERAPEUTIC SKEPTICISM REVISITED}

Pharmaceutical progress accelerated dramatically between the 1940 s and the 1960s. Even in the context of other 20th-century therapeutic revolutions - such as psychoanalysis and cardiac surgery - the midcentury surge in pharmaceutical therapy stands out. More than 4500 new drug products entered the U.S. market in the 1950s as industry churned out new classes of therapeutic agents: broad-spectrum antibiotics, antidiabetic agents, antihypertensives, antipsychotics, antidepressants, and cholesterol-lowering medications. Of every dollar spent on pharmaceuticals in 1961, 70 cents went to drugs that had been unavailable just 10 years earlier (1962a).

This new enthusiasm pro- voked new forms of skepticism. By the Journal's sesquicentennial year, Louis Goodman and other clinical pharmacologists echoed Holmes in bemoaning the "therapeutic jungle" of the 1950s wonder drugs. Other critics were concerned by what they saw as the "brainwashing" of clinicians by pharmaceutical marketing (see Fig. 4). These concerns were reflected in televised hearings on the marketing practices of the prescription-drug industry orchestrated by Senator Estes Kefauver from 1959 to 1962. The Journal offered blow-by-blow coverage of the hearings, focusing on the need for the Food and Drug Administration to formally adjudicate therapeutic efficacy and transform the research and development process $(1960 \mathrm{a}, 1960 \mathrm{~b}$, 1961a, 1961b, 1961c).

However, passage of the Kefauver-Harris Amendments of 1962, which gave rise to the structure of phase 1, 2, and 3 clinical trials for demonstrating therapeutic efficacy, owed as much to the thalidomide tragedy as to Kefauver's efforts. The horrors of thalidomide, the sedative-antinauseant that caused limb-reduction malformations in children of women who took the drug while pregnant, extended beyond the drug itself (2011b); as a Journal editorial noted, given the furious pace of pharmaceutical development, marketing, and consumption, "only continued and increasing vigilance can prevent the experience from being repeated" (1962b). Outside the medical profession, thalidomide would inspire even more nihilistic perspectives, embodied in popular works such as Morton Mintz's The Therapeutic Nightmare and Ivan Illich's Medical Nemesis. The specter of iatrogenesis these books invoked continues 
to haunt practice, from thalidomide to Vioxx, from DES to Avandia.

Extending this renaissance of skepticism, some questioned the overall role of medicine itself in improving public health. In 1962, the physician-demographer Thomas McKeown published an analysis of the decline of tuberculosis in England and Wales. ${ }^{5}$ Noting that the decline had begun before the bacillus was discovered and had nearly concluded before streptomycin was developed, McKeown argued that modern therapeutics had been falsely credited with public health improvements that could be better explained by secular changes in nutrition and standards of living. Similarly, those attempting to bring the benefits of modern tuberculosis drugs to impoverished populations in the 1960s realized that drugs were necessary but not sufficient for transforming health - a lesson that would be relearned through global efforts to treat malaria, tuberculosis, and HIV infection in the 21 st century (2006). ${ }^{6}$
RECONTEXTUALIZING THERAPEUTICS

From the leeches, lancets, and purgatives of the early 1800 s to today's targeted molecular medicines, doctors have constantly sought new and better therapies. Yet the evolution of the field of therapeutics has not been linear, and none of the therapeutic revolutions of the past two centuries have been immediate or complete. Rather, our field's progress owes as much to changing forms of therapeutic skepticism as to changing forms of therapeutic enthusiasm.

As the locus of disease has narrowed from the afflicted person to the molecular mechanism, and the target of magic bullets has followed suit, physicians have faced regular reminders of the limits of the reductionist approach. The history of therapeutics offers a space to reflect on these more subtle logics of medical knowledge and practice, restoring our appreciation for the breadth of the physician's task and the complexity of our mission.
Disclosure forms provided by the authors are available with the full text of this article at NEJM.org.

From the Department of the History of Medicine and the Department of Medicine, Johns Hopkins University School of Medicine, Baltimore (J.A.G.); the Department of Global Health and Social Medicine, Harvard Medical School (D.S.J., S.H.P.), and the Center for the History of Medicine, Countway Library of Medicine (S.H.P.) - both in Boston; and the Department of the History of Science, Harvard University, Cambridge, MA (D.S.J.).

This article was updated on September 20, 2012, at NEJM.org.

1. Rosenberg CE. The therapeutic revolution. In: Vogel MS, Rosenberg CE, eds. The therapeutic revolution: essays on the social history of American medicine. Philadelphia: University of Pennsylvania Press, 1979:9-31. 2. Warner JH. The therapeutic perspective: medical practice, knowledge, and identity in America: 1820-1885. Cambridge, MA: Harvard University Press, 1987.

3. Pernick M. A calculus of suffering: pain, professionalism, and anesthesia in 19th century America. New York: Columbia University Press, 1987.

4. Brandt AM. No magic bullet: a social history of venereal disease in the United States since 1880. New York: Oxford University, 1985.

5. McKeown T, Record RG. Reasons for the decline of mortality in England and Wales during the nineteenth century. Popul Stud 1962;16:94-122.

6. Jones DS. The health care experiments at Many Farms: the Navajo, tuberculosis, and the limits of modern medicine, 1952-1962. Bull Hist Med 2002;76:749-90.

DOI: 10.1056/NEJMp1113570

Copyright @ 2012 Massachusetts Medical Society.

\section{Punishing Health Care Fraud — Is the GSK Settlement Sufficient?}

Kevin Outterson, J.D., LL.M.

\begin{abstract}
$\mathrm{O}$ n July 2, 2012, the Department of Justice announced the largest settlement ever in a case of health care fraud in the United States. GlaxoSmithKline (GSK) agreed to plead guilty to three criminal counts and settle civil charges brought under various federal statutes; the company will pay a total of $\$ 3$ billion to the federal government and participating states. Since 2009, the federal
\end{abstract}

government has collected more than $\$ 11$ billion in such settlements under the False Claims Act.

In the Federal District Court in Boston a few days later, GSK pleaded guilty to two criminal counts for sales of misbranded Paxil (paroxetine) and Wellbutrin (bupropion). These drugs are considered misbranded when they are promoted for indications for which they have not been approved by the
Food and Drug Administration the practice commonly known as off-label promotion. Providers cannot be reimbursed for misbranded drugs under federal and state rules. GSK also pleaded guilty to a third crime, failing to report safety data related to Avandia (rosiglitazone). Failing to report safety data violates the Food, Drug, and Cosmetic Act and leads to serious questions about wheth- 